\title{
Making Milk Less Allergenic
}

Fiona A. Ewart ${ }^{1}$

\section{HALIFAX WEST HIGH SCHOOL}

\section{Abstract}

The formation of stable aggregates by food proteins is associated with allergenicity. In particular, amyloid formation by the fish allergen parvalbumin was recently shown to favor $\operatorname{IgE}$ binding and subsequent allergic recognition. Therefore, reducing amyloid content in an allergenic food might offer a direct way to make that food less likely to trigger an allergy. In this project, protein aggregation and amyloid formation were studied in milk using gel electrophoresis and fluorescence-based assays. The results suggested that ordinary pasteurized milk from the grocery store contained protein aggregates and specifically amyloid. Processing the milk as normally done during food preparation did not appreciably affect general aggregation or amyloid formation. However, the addition of some polyphenol-containing food products to the milk appeared to result in reduced amyloid levels. Moreover, cranberry juice also appeared to reduce amyloid formation by the milk protein casein. These results suggest that the addition of cranberry or other polyphenol-rich foods to milk products for young children may reduce the risk of milk allergy development by diminishing protein aggregation.

\section{Key Words}

Allergy, aggregation, amyloid, anaphylaxis, milk, protein

\section{Introduction}

Allergies continue to be an unresolved health problem in society. Some foods tend to be more allergenic than others. For example, Health Canada recognizes ten foods as priority allergens because they cause the most allergic reactions [1].

Proteins in foods cause allergic responses when immunoglobulin $\mathrm{E}(\mathrm{IgE})$ recognizes specific amino acid sequences on the protein surfaces called epitopes. IgE molecules work in pairs and therefore they respond most strongly to proteins that pair up or group together to form larger aggregates [2]. For this reason, a protein can be an allergen if it has a surface epitope that an IgE molecule can bind to and if it forms groups of repeated epitopes that can bind $\operatorname{IgE}$ molecules together. These crosslinked IgEs activate mast cell and basophils, which then trigger an allergic reaction [3]. Allergenic proteins tend to be very stable. They are often highly resistant to digestion and to heat (reviewed by [4]). When protein aggregates resist digestion, they can be absorbed intact through broken skin or in the digestive tract. This makes their surface epitopes available to be recognized by IgE pairs, which could lead to allergy.

Recent studies have shown that one way in which a protein can form stable allergenic aggregates is by forming amyloid. Amyloid refers to a shape that is formed easily by some proteins. When protein molecules convert to the amyloid shape, they are tightly folded and able to polymerize. For example, codfish parvalbumin protein was found to form amyloid and this was reported to be allergenic. Specifically, this arrangement of parvalbumin molecules was recognized by $\mathrm{IgE}$, which triggered an allergic response [5,6]. When the parvalbumin amyloid was treated with the compound epigallocatechin gallate (EGCG), causing it to unfold, it was no longer allergenic $[5,6]$.

One method being explored to prevent the development of allergies is to favor immune tolerance by introducing foods in the first months of life (reviewed by [7]). However, if the first exposure to a protein results in its binding to an $\operatorname{IgE}$ pair, then the resulting IgE immunological memory would result in the development of allergy instead. Therefore, if protein aggregation, and especially amyloid formation, could be reduced or prevented in foods, then introducing those foods early would be most likely to induce tolerance rather than an allergy.

The goal of this study was to reduce protein aggregation in milk to mitigate its allergenicity and increase the likelihood of tolerance in young children. The study focuses on milk protein because dairy is widespread in foods and difficult to strictly avoid. Furthermore, allergic reactions to milk have caused the loss of young lives in Canada. If immune tolerance to milk could be induced in early childhood to prevent allergy development, it could increase the quality of life of many patients and reduce health care costs. Therefore, in this study, protein aggregation and amyloid content were examined in milk processed in different ways. Then, methods of treating milk protein to reduce amyloid formation were evaluated. 


\section{Materials and Methods}

\section{Materials}

Three items were purchased at local grocery stores in Halifax, Nova Scotia, including pasteurized whole (homogenized) milk containing 3.25\% milk fat (Baxter, Saint John, NB), pasteurized "no name" (Atlantic Superstore brand, Loblaws Companies, Brampton, ON) skim milk powder, and "All in 1 Powerball" dishwasher detergent cubes (Finish ${ }^{\circledR}$, Reckitt Benckiser, Mississauga, ON). Three additional items were purchased from Pete's Fine Foods, in Halifax, Nova Scotia. These included pure cranberry juice (Terra Beata Farms, Lunenburg, NS), dried bladderwrack seaweed (Fucus vesiculosus; Naturally Nova Scotia, Lawrencetown, NS) and maple syrup (Acadian Maple Products, Tantallon, NS). EGCG was obtained from Sigma-Aldrich (St. Louis, MO). All other materials and reagents were from chemical suppliers.

\section{Study Design}

The research plan was to treat the milk in ways that correspond to normal food preparation and to examine the proteins. The plan is outlined in Figure 1.

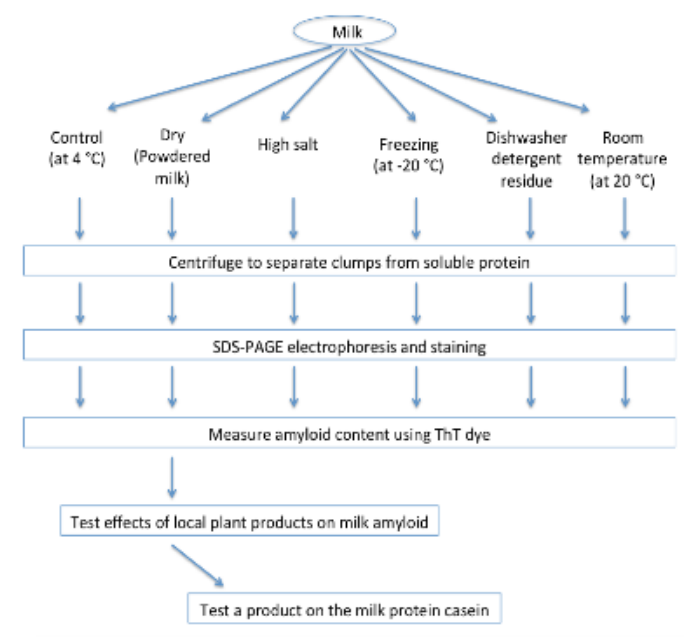

Figure 1. Diagram illustrating the milk allergy project plan.

\section{Milk Sample Preparation}

Homogenized liquid milk was used because this is the form most often recommended for young children under the age of two. One-mL samples of homogenized milk were pipetted into $1.5-\mathrm{mL}$ micro-centrifuge tubes. Powdered milk was prepared by dissolving $8 \mathrm{~g}$ of milk powder into $250 \mathrm{~mL}$ of water and stirring until dissolved.

\section{Sample Treatments}

Samples were processed under conditions corresponding to those encountered in normal food preparation within a kitchen. These include different temperatures, the addition of salt (as in soups, casseroles and other foods), various storage conditions, and residual traces of dishwasher detergent, as might occur on dishes. Sets of three samples were treated as indicated in Table 1. Following treatments, the samples were centrifuged in a micro-centrifuge (Beckman Coulter, Mississauga, ON) at 10,000 revolutions per minute for 10 minutes. The supernatants from each tube were transferred to new tubes and then the pellets were dissolved in 990 $\mu \mathrm{L}$ of water by vortexing and briefly shaking.

Table 1. Processing of milk prior to aggregate analysis.

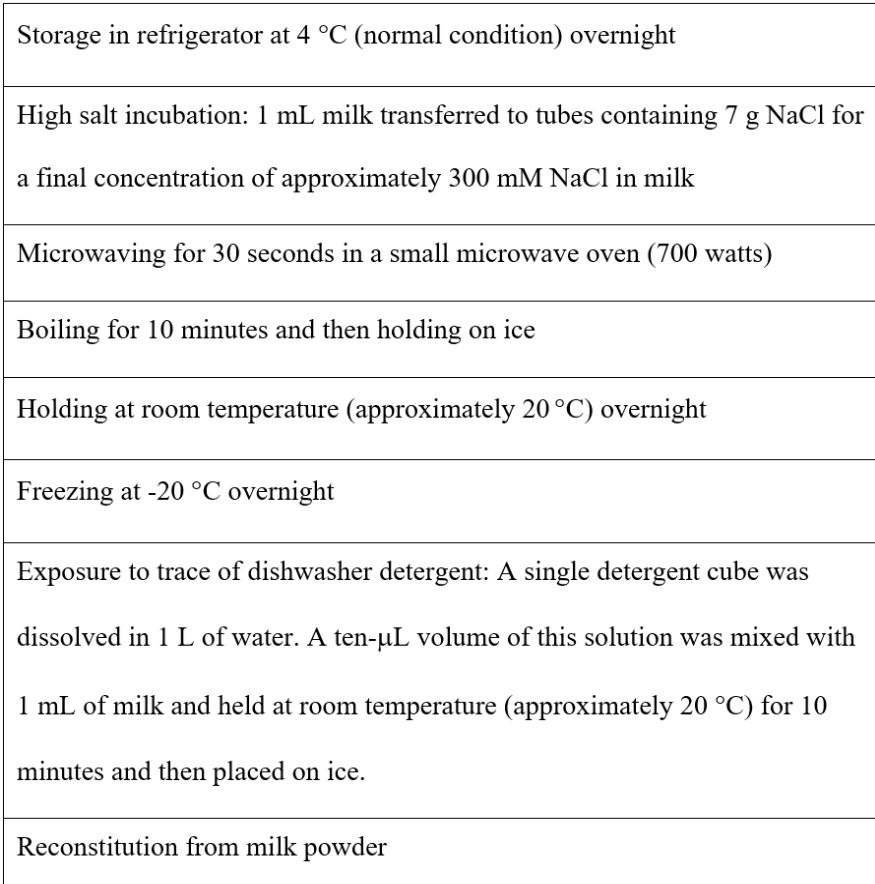

Analysis by sodium dodecyl sulfate-polyacrylamide gel electrophoresis (SDS-PAGE)

Samples were diluted 1 in 10 by combining $100 \mu \mathrm{L}$ with 900 $\mu \mathrm{L}$ of water and mixing well. Then, $3 \mu \mathrm{L}$ from each of these tubes were transferred to new tubes to run on the gel. All procedures were done following the instructions provided by the gel apparatus manufacturer (Bio-Rad Laboratories, Mississauga, ON). Three $\mu \mathrm{L}$ of SDS-PAGE sample buffer was added to each sample, they were heated to $70{ }^{\circ} \mathrm{C}$ for 10 minutes, and then these were loaded into the lanes of a $12 \%$ acrylamide SDS-PAGE gel. Protein molecular 
weight standards (VWR Scientific, Mississauga, ON) were also run on one lane per gel. The gels were run at $150 \mathrm{~V}$ for 80 minutes and then stained overnight in GelCode Blue stain (ThermoFisher Scientific, Waltham, MA).

\section{Thioflavin T fluorescence assay}

For each assay set, a $50 \mathrm{mM}$ solution of thioflavin $\mathrm{T}$ (ThT) was prepared in warm water under low light. It was then filtered in a $0.45 \mu \mathrm{m}$ filter disk attached to a syringe. A ten- $\mu \mathrm{L}$ of filtered dye was diluted into $10 \mathrm{~mL}$ of glycine- $\mathrm{NaOH}$ buffer, $\mathrm{pH} 8.5$ to make the working solution. For assays, $10 \mu \mathrm{L}$ of sample or buffer blank were transferred into each well of a black-sided Greiner Bio-One microtiter plate (VWR Scientific, Mississauga, ON). Then, $250 \mu \mathrm{L}$ of the ThT working solution were transferred into each well. Using a microtiter plate reader (Molecular Devices, San Jose, CA) set to fluorescence detection mode, the plate was illuminated with a blue light at $450 \mathrm{~nm}$ and then blue-green light emission was detected at $482 \mathrm{~nm}$. For each experiment, blanks containing identical solutions with no protein were also measured so that background values could be subtracted. The data were analyzed and graphs were prepared using Excel.

\section{Treatment of milk with other foods}

Powdered milk was used for these experiments because it had the lowest ThT fluorescence readings of the untreated samples. The milk powder was dissolved in water as described above but at half the original concentration. Equal portions were treated with natural products that could be expected to reduce amyloid levels. These included cranberry juice, maple syrup, and seaweed extract obtained as noted above. The seaweed was previously ground, dissolved in ethanol, and centrifuged to obtain its ethanol-soluble components. In addition, $9 \mathrm{mg} / \mathrm{mL}$ EGCG from green tea was used. The powdered milk was also combined with equivalent volumes of water as a control for cranberry juice, maple syrup and EGCG, which were aqueous, and combined with equivalent volumes of ethanol as a control for the seaweed extract, which was dissolved in ethanol. The samples were incubated in at $4 \mathrm{oC}$ for 48 hours and then they were analyzed using the ThT assay.

Treatment of the milk protein casein with cranberry juice

The effect of cranberry juice on the milk protein casein was further studied. Cranberry juice was prepared in a series of dilutions in water. Casein solution $(10 \mathrm{mg} / \mathrm{mL})$ was prepared in $100 \mathrm{mM}$ 2-(N-morpholino)ethanesulfonic acid, $\mathrm{pH}$ 6.5. Identical volumes of casein solution were combined 1:1 with each of the cranberry juice dilutions and with water as a control. They were incubated at $37^{\circ} \mathrm{C}$ to favour amyloid formation for 48 hours and then analyzed by ThT assay.

\section{Results}

Effects of milk processing on aggregation

With all treatments, the major milk proteins stayed mostly soluble (Figure 2). However, insoluble protein was present in all samples as well (Figure 2). Protein bands were identified based on earlier studies [8]. Treatment with dishwasher detergent cut one of the proteins into two fragments. The levels of beta-casein diminished in the soluble and insoluble protein fractions and fragments were visible in the soluble protein fraction. Boiling resulted in more insoluble protein material, whereas microwaving treatment showed less. Overall, however, there were no large shifts in the proportions of soluble and insoluble protein with any of the treatments.
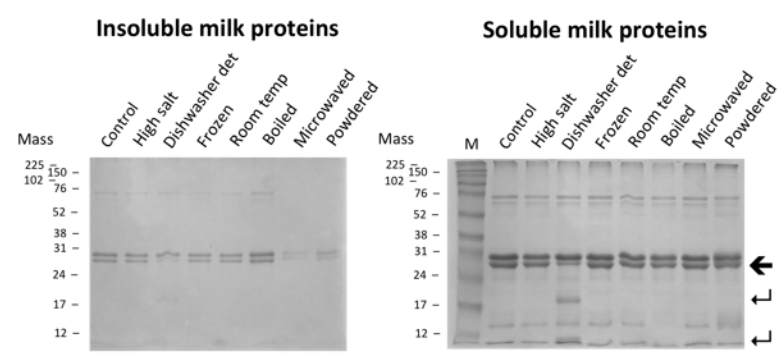

Figure 2. SDS-PAGE analysis of milk proteins following centrifugation. Proteins were separated on a $12.5 \%$ acrylamide gel and stained with GelCode Blue. Treatments are listed above lanes and " $\mathrm{M}$ " indicates molecular weight marker proteins. The position of the beta-casein bands is indicated by the large arrow and the positions of the fragments are indicated by the small arrows.

\section{Effects of milk processing on ThT fluorescence}

The levels of ThT fluorescence were substantially higher in the soluble milk protein than in the insoluble pellets; however, there was measurable fluorescence present in every sample after subtracting milk-free blank values for ThT (Figure 3). The fluorescence was not caused by the milk protein, since in separate experiments the milk did not fluoresce on its own in the assay without ThT addition. The fluorescence results shown in Figure 3 suggested that fresh milk directly from the grocery store contained amyloid. Moreover, some samples contained different average amounts, but they were very similar overall. 


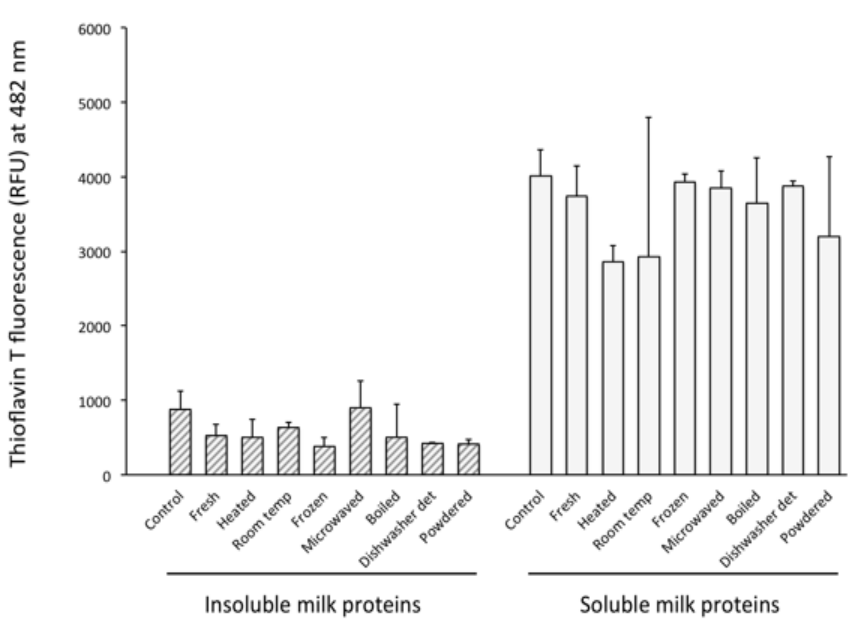

Figure 3. Detection of ThT fluorescence in the presence of milk proteins. Protein samples were added to ThT dye solution. Samples were exposed to blue light at $450 \mathrm{~nm}$ and fluorescence was detected by measuring blue-green light at $482 \mathrm{~nm}$. Data shown are means with standard deviations $(n=3)$.

Effects of other foods on ThT fluorescence in milk

Food ingredients, including EGCG, bladderwrack (a seaweed) and cranberry juice, appeared to reduce the ThT fluorescence levels in powdered milk (Figure 4). However, maple syrup did not appear to have any effect. Since cranberry juice and seaweed had the greatest effect on ThT fluorescence levels, these were both of interest for further study. However, the seaweed was extracted in ethanol, which is a molecule that is not ideal in a milk product for children. Therefore, the cranberry juice was the best candidate for further study.

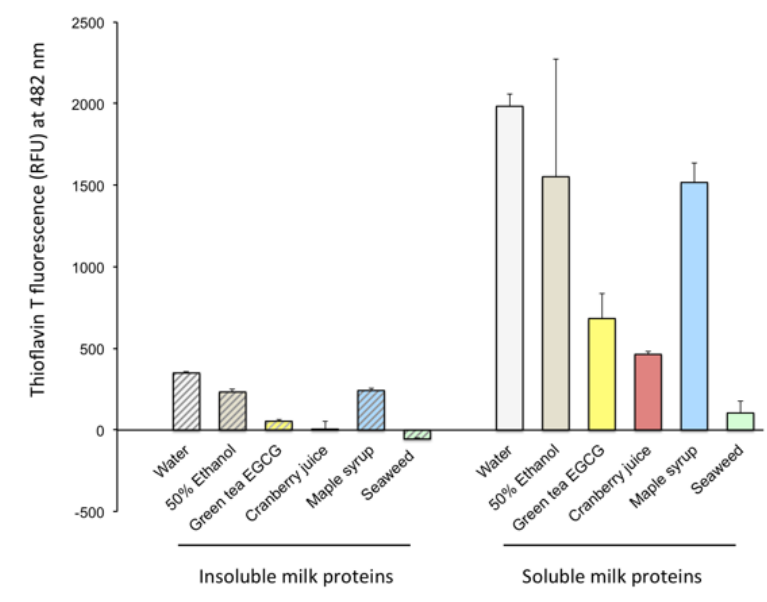

Figure 4. Reduction in ThT fluorescence in the presence of milk amyloid with treatments. Fluorescence was measured in the treated and untreated milk samples containing identical concentrations of milk. Treated samples contained $50 \%$ cranberry juice, $9 \mathrm{mg} / \mathrm{mL}$ EGCG, 50\% maple syrup or 50\% seaweed extract and controls contained water or $50 \%$ ethanol (for seaweed control only). Data shown are means with standard deviations $(\mathrm{n}=3)$.

The effect of cranberry juice on ThT fluorescence in casein samples

The effect of cranberry juice on amyloid formation by the milk protein casein was evaluated (Figure 5). The graph suggested diminishing ThT fluorescence with an increasing amount of cranberry juice. The average ThT fluorescence levels in the casein protein incubated with $50 \%$ juice was less than half that with the control ( $0 \%$ juice), suggesting a far lower level of amyloid in these treated samples.

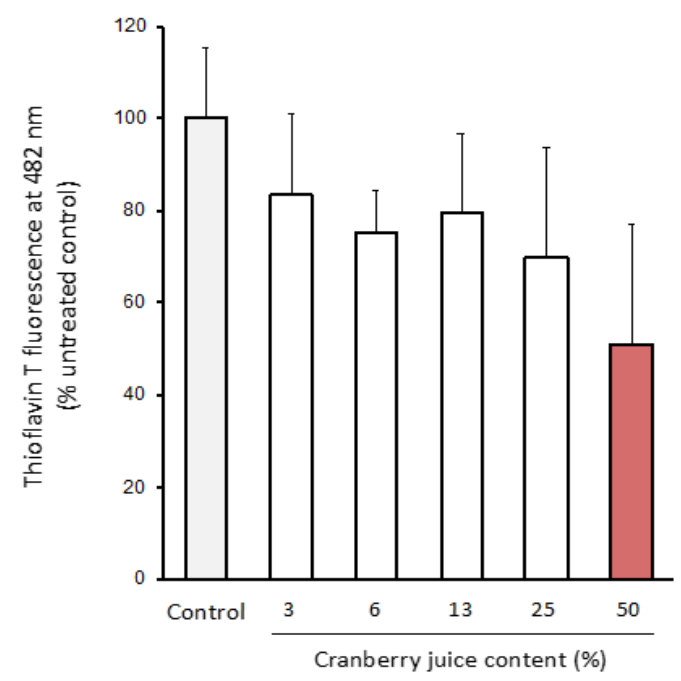

Figure 5. Effect of cranberry juice levels on ThT fluorescence in the presence of casein. Casein samples were incubated at $37{ }^{\circ} \mathrm{C}$ in the absence of cranberry juice (control) and in the presence of cranberry juice at various concentrations. Data shown are means with standard deviations $(\mathrm{n}=3)$

\section{Discussion}

Protein aggregates in general, and more specifically protein in amyloid form, appeared to be present in each of the milk samples according to the ThT fluorescence results. These results suggest that protein aggregates and amyloid are a typical feature of milk and that routine food preparation procedures have no major effects 
on their formation. Although earlier studies have shown amyloid formation by the specific milk proteins lactalbumin and casein in isolation $[9,10]$, and raw milk was previously shown to generate ThT fluorescence [11], this study is the first to show that proteins can form measurable amyloid in ordinary grocery store milk.

The trace of dishwasher detergent was not used to represent a food preparation method, but to include a possible result of normal dishwasher use. The prevalence of certain non-food allergies appeared to be higher among people who used automatic dishwashers than among those who hand-washed dishes [12]. Therefore, it was justified to examine the effect of residual dishwasher detergent on milk protein aggregation. Although no

appreciable effect on protein aggregation or amyloid formation was observed, the enzymes that are present in the dishwasher detergent appeared to break the casein into two smaller fragments. Since casein can form amyloid, it might be interesting in future to investigate these fragments to determine whether they aggregate or form amyloid more easily than the whole casein.

Polyphenols have been shown to reduce the allergenicity of proteins $[13,14]$, but the mechanism of their effect is not well understood. Since polyphenols diminish amyloid folding and fibril formation (reviewed by [15]) and since amyloid has a role in allergenicity $[5,6]$ a reduction in amyloid structure could be the reason for their anti-allergic effect. The polyphenol EGCG was found to reduce the amyloid content and allergenicity of parvalbumin [5]. Similarly, EGCG was found to reduce the levels of amyloid in milk in this study, as did cranberry juice and seaweed extract. Cranberry juice was chosen for closer study here because it caused a major reduction in milk amyloid content and because it is a product that could be easily added to children's foods.

Casein proteins naturally form aggregates and they are some of the proteins associated with persistent milk allergy $[16,17]$. Therefore, the effect of cranberry juice on casein solutions was explored. Casein solutions containing cranberry juice appeared to have lower levels of amyloid than identical solutions incubated without it. Also, increasing concentrations of juice appeared to result in progressively diminishing amyloid levels. This suggests that cranberry juice could be a useful additive in milk products that are being fed to young children in order to reduce amyloid levels. It will also be interesting to determine whether other common fruits such as blueberries or strawberries have the same effect as cranberries since many different fruits contain polyphenol molecules.

Besides the occurrence of amyloid in milk shown here and parvalbumin $[5,6]$ in cod, amyloid formation has been reported in commonly allergenic foods such as soy protein [18], egg white [19 and latex [20]. If the amyloid-forming proteins are found to be the allergenic ones in these products, then modifying amyloid content by combining them with foods containing polyphenols might offer a way to prevent the development of allergies to a variety of foods and other products.

\section{Dedication}

In Canada, milk allergy caused the deaths of Sabrina Shannon (age 13, in 2003) and Caroline Lorette (age 14, in 2014) and may have had a role in the death of Andrea Mariano (age 18, in 2015). This research study is dedicated to their memory.

\section{Acknowledgements}

I would like to thank Mr. Nathan Weatherbee-Martin for introducing me to SDS-PAGE and the apparatus used and Dr. David Waisman for letting me use his fluorescence microplate reader and incubator (both Dalhousie University). I am grateful to my former science teacher Ms. Amy Mercer for her support. I also thank Ms. Chantell Cleversey and Dr. Vanya Ewart (Dalhousie University) for the seaweed extract, and Dr. Vanya Ewart for training in laboratory safety and research methods. In addition, I thank Drs. Vanya and Stephen Ewart for reviewing the manuscript. I especially appreciate all the encouragement from Ms. Jan Lorette and the Sweet Caroline Foundation (http://www.sweetcarolinefoundation.ca). 


\section{References}

1. Health Canada Priority Allergens. Health Canada [Internet]. 2017 [cited 12 Feb 2018]. Available at: http://www.hc-sc.gc.ca/fn-an/securit/allerg/fa-aa/ index-eng.php

2. Masilamani M, Commins S, Shreffler W. Determinants of food allergy. Immunol Allergy Clin North Am [Internet]. 2012 [cited 12 Feb 2018 ]; 32 : 11-33. Available from: https://www.ncbi.nlm.nih.gov/pubmed/22244230

3. Benedé S, Garrido-Arandia M, Martín-Pedraza L, Bueno C, Díaz-Perales A, Villalba M. Multifactorial modulation of food-induced anaphylaxis. Front Immunol [Internet]. 2017 [cited 10 July 2018]; 16; 552. Available from: https://doi.org/10.3389/fimmu.2017.00552

4. Lorenz AR, Scheurer S, Vieths S. Food allergens: molecular and immunological aspects, allergen databases and cross-reactivity. Chem Immunol Allergy [Internet]. 2015 [cited 12 Feb 2018]; 101: 18-29. Available from: https://www.ncbi.nlm.nih.gov/pubmed/26022861

5. Martinez J, Sanchez R, Castellanos M, Fernandez-Escamilla AM, Vazquez-Cortes S, Fernandez-Rivas M, Gasset M. Fish $\beta$-parvalbumin acquires allergenic properties by amyloid assembly. Swiss Med Wkly [Internet]. 2015 [cited 12 Feb 2018]; 145: w14128. Available from: https://www.ncbi.nlm.nih. gov/pubmed/26023765

6. Sanchez R, Martinez J, Castro A, Pedrosa M, Quirce S., Rodriguez-Perez R, Gasset, M. The amyloid fold of Gad $\mathrm{m} 1$ epitopes governs IgE binding. Sci Rep [Internet]. 2016 [cited 12 Feb 2018]; 6, 32801. Available from: https://www.ncbi.nlm.nih.gov/pubmed/27597317

7. Peters RL, Dang TD, Allen KJ. Specific oral tolerance induction in childhood. Pediatr Allergy Immunol [Internet]. 2016 [cited 12 Feb 2018 ]; 27 : 784794. Available at: https://www.ncbi.nlm.nih.gov/pubmed/27496561

8. Conway V, Gauthier SF, Pouliot Y. Effect of cream pasteurization, microfiltration and enzymatic proteolysis on in vitro cholesterol-lowering activity of buttermilk solids. Dairy Sci Technol [Internet]. 2010 [cited 12 Feb 2018]; 90: 449-460. Available at: https://www.dairy-journal.org/articles/dst/ abs/2010/03/dst0972/dst0972.html

9. Goers J, Permyakov SE, Permyakov EA, Uversky VN, Fink AL. Conformational prerequisites for alpha-lactalbumin fibrillation. Biochemistry [Internet]. 2002 [cited 12 Feb 2018]; 41: 12546-12551. Available at: https://www.ncbi.nlm.nih.gov/pubmed/12369846

10. Holt C, Carver JA, Ecroyd H, Thorn DC. Caseins and the casein micelle: their biological functions, structures, and behavior in foods. J Dairy Sci [Internet]. 2013 [cited 12 Feb 2018]; 96: 6127-6146. Available at: https://www.ncbi.nlm.nih.gov/pubmed/23958008

11. Lencki RW. Evidence for fibril-like structure in bovine casein micelles. J Dairy Sci. [Internet]. 2007 [cited 12 Feb 2018]; 90: 75-89. Available at: https:// www.ncbi.nlm.nih.gov/pubmed/17183077

12. Hesselmar B, Hicke-Roberts A, Wennergren G. Allergy in children in hand versus machine dishwashing. Pediatrics [Internet]. 2015 [cited 12 Feb 2018 ]; 135: e590-597. Available at: https://www.ncbi.nlm.nih.gov/pubmed/25713281

13. Plundrich NJ, Kulis M, White BL, Grace MH, Guo R, Burks AW, et al. Novel strategy to create hypoallergenic peanut protein-polyphenol edible matrices for oral immunotherapy. J Agric Food Chem [Internet]. 2014 [cited 12 Feb 2018]; 62: 7010-7021. Available at: https://www.ncbi.nlm.nih.gov/ pubmed $/ 24758688$

14. Singh A, Demont A, Actis-Goretta L, Holvoet S, Leveques A, Lepage M, et al. Identification of epicatechin as one of the key bioactive constituents of polyphenol-enriched extracts that demonstrate an anti-allergic effect in a murine model of food allergy. Br J Nutr [Internet]. 2014 [cited 12 Feb 2018 ]; 112: 358-368. Available at: https://www.ncbi.nlm.nih.gov/pubmed/24854295

15. Bieschke, J. Natural compounds may open new routes to treatment of amyloid diseases. Neurotherapeutics [Internet]. 2013 [cited 12 Feb 2018]; 10: 429439. Available at: https://www.ncbi.nlm.nih.gov/pubmed/23670234

16. Roth-Walter R, Berin MC, Arnaboldi P, Escalante CR, Dahan S, Rauch J, et al. Pasteurization of milk proteins promotes allergic sensitization by enhancing uptake through Peyer's patches. Allergy [Internet]. 2008 [cited 12 Feb 2018]; 63: 882-890. Available at: https://www.ncbi.nlm.nih.gov/ pubmed/18588554

17. Kuitunen M, Englund H, Remes S, Moverare R, Pelkonen A, Borres MP, Makela MJ. High IgE levels to $\alpha$-lactalbumin, $\beta$-lactoglobulin and casein predict less successful cow's milk oral immunotherapy. Allergy [Internet]. 2015 [cited 12 Feb 2018]; 70: 955-962. Available at: https://www.ncbi.nlm.nih. gov/pubmed/25951431

18. Tang CH, Wang CS. Formation and characterization of amyloid-like fibrils from soy $\beta$-conglycinin and glycinin. J Agric Food Chem [Internet]. 2010 [cited 12 Feb 2018]; 58: 11058-11066. Available at: https://www.ncbi.nlm.nih.gov/pubmed/20919718

19. Azakami H, Mukai A, Kato A. Role of amyloid type cross beta-structure in the formation of soluble aggregate and gel in heat-induced ovalbumin. J Agric Food Chem [Internet]. 2005 [cited 12 Feb 2018]; 53: 1254-1257. Available at: https://www.ncbi.nlm.nih.gov/pubmed/15713049

20. Berthelot K, Lecomte S, Estevez Y, Coulary-Salin B, Bentaleb A, Cullin C, et al. Rubber elongation factor (REF), a major allergen component in Hevea brasiliensis latex has amyloid properties. PLoS One [Internet]. 2012 [cited 12 Feb 2018]; 7: e48065. Available at: https://www.ncbi.nlm.nih.gov/ pubmed/23133547 


\section{Graphical abstract}

The results of this study suggest a new and exciting possibility for reducing the development of milk allergy in young children and this strategy may be applicable to other allergens. The diagram below shows how amyloid reduction could be used to reduce the risk of developing a milk allergy.

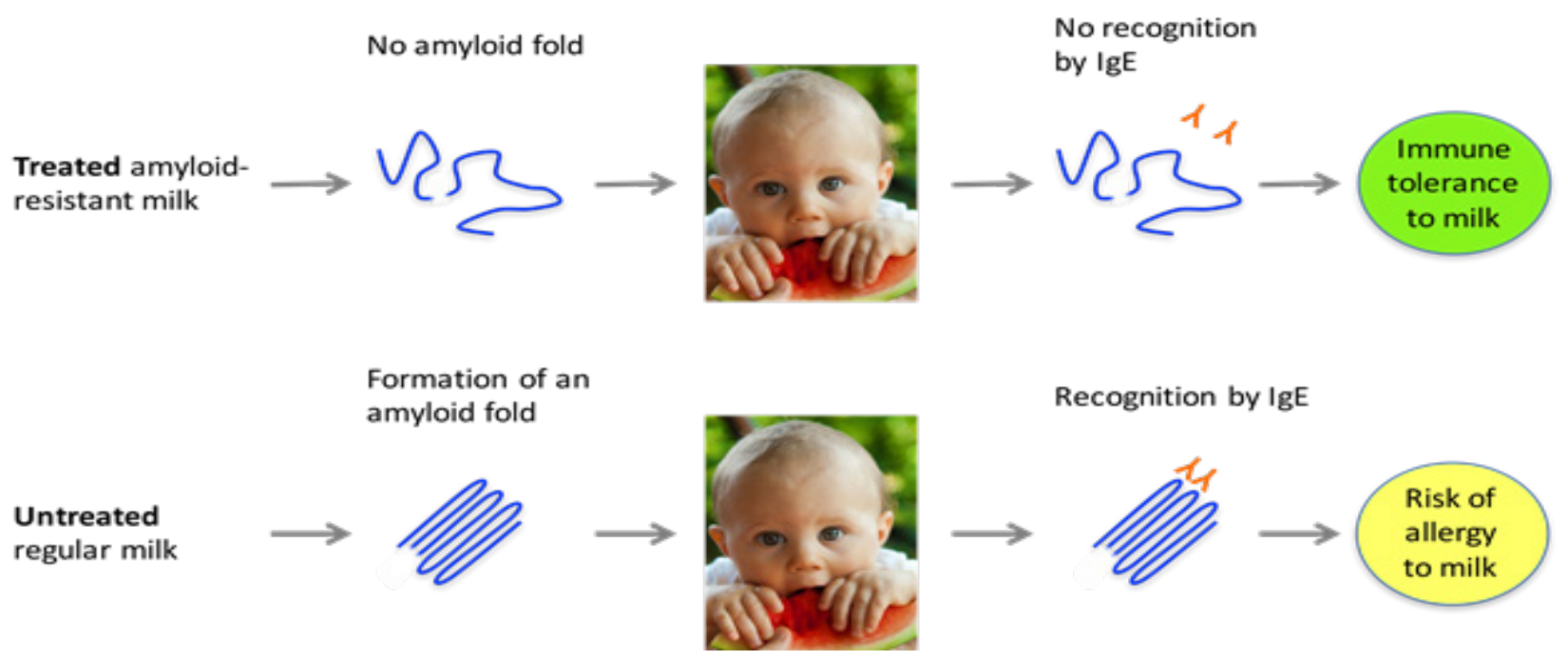

